\title{
Lamellar macular hole formation following vitrectomy for rhegmatogenous retinal detachment repair
}

This article was published in the following Dove Press journal:

Clinical Ophthalmology

II April 2012

Number of times this article has been viewed

\author{
Tina Xirou \\ Andrej Kidess \\ Christina Kourentis \\ Vasiliki Xirou \\ Elias Feretis \\ Stamatina A Kabanarou \\ Retina Department, Hellenic Red \\ Cross General Hospital, Athens, \\ Greece
}

Correspondence: Stamatina A Kabanarou 2 Nikitara Street, N Psychiko I54 5I, Athens, Greece

Tel +306944376612

$\mathrm{Fax}+302106414396$

Email stamatina_k@hotmail.com
Background: The purpose of this study was to investigate lamellar macular hole formation in six patients after rhegmatogenous retinal detachment repair.

Methods: A retrospective review of medical records of patients who underwent primary pars plana vitrectomy for rhegmatogenous retinal detachment repair was performed. Optical coherence tomography characteristics and best-corrected visual acuity were evaluated. Patients who developed lamellar macular hole after pars plana vitrectomy for rhegmatogenous retinal detachment repair were identified.

Results: A total of 1185 eyes underwent pars plana vitrectomy for retinal detachment between 2004 and 2009. Optical coherence tomography evaluation was available in 450 cases. Six of these cases demonstrated lamellar macular hole formation, which was diagnosed by OCT-3. The mean time from retinal detachment surgery to lamellar hole diagnosis was 4.1 months. The presence of an epiretinal membrane on the surface of the juxtafoveal retina was a common finding in all six patients. Visual acuity was improved after successful retinal reattachment and remained unchanged after lamellar hole formation.

Conclusion: Lamellar macular holes developing after pars plana vitrectomy is a rare complication. Stability of optical coherence tomography findings and best-corrected visual acuity after lamellar macular hole formation may be observed for at least two years.

Keywords: lamellar macular hole, rhegmatogenous retinal detachment

\section{Introduction}

Lamellar macular hole (LMH) is an old term, first described by Gass in 1975 as a foveal lesion that resulted from cystoid macular edema. ${ }^{1} \mathrm{~A}$ LMH is defined as a partial thickness macular hole where the inner layers of the fovea are involved with traction and detached from the underlying cellular layers of the fovea, leaving the photoreceptor layer intact. LMH has been described in patients with diabetic cystoid macular edema ${ }^{2}$ and in highly myopic eyes. ${ }^{3,4} \mathrm{~A}$ LMH is also occasionally seen in eyes with chronic cystoid macular edema associated with old retinal vein occlusion. ${ }^{5,6}$ Gass suggested that LMH could be histopathologically related to cystoid macular edema and epiretinal membrane, ${ }^{1}$ and these findings were later confirmed by technological advances in optical coherence tomography (OCT)..$^{7-15}$

Although many reports had been found regarding full thickness LMH formation following vitrectomy, ${ }^{16-21}$ we did not find any previous reports on $\mathrm{LMH}$ formation after vitrectomy for rhegmatogenous retinal detachment (RRD) repair. The purpose of our study is to report a case series of LMH formation following RRD repair, 
optical coherence tomography (OCT) characteristics, and best-corrected visual acuity outcome during a follow-up period of two years.

\section{Materials and methods}

We retrospectively reviewed the medical records of all patients who had undergone primary pars plana vitrectomy for RRD repair between 2004 and 2009 (1185 eyes). The patients had been operated on by three different surgeons. OCT was not performed routinely in all retinal detachment cases postoperatively. However, patients in whom postoperative best-corrected visual acuity was not improved or abnormal findings were observed at the macula during funduscopy were referred for OCT.

OCT imaging was available in 450 cases. We were able to identify six patients (six eyes) who developed LMH after RRD repair based on their OCT. The data collected also included age, gender, Snellen best-corrected visual acuity at the time of retinal detachment and following successful reattachment, the surgical procedure performed, and the time from retinal detachment surgery to lamellar hole formation. The diagnosis of LMH was confirmed postoperatively using an OCT-3 (Carl Zeiss Meditec, Dublin, CA). Central foveal thickness was also measured on OCT images and was defined as the distance between the vitreoretinal interface and retinal pigment epithelium in the fovea.

\section{Results}

Four men and two women of mean age $69 \pm 11$ (range 58-80) years were found to develop LMH after RRD repair. All patients had a preoperative visual acuity of 20/200 or worse. The fovea had been detached in all eyes at the time of RRD repair.

All six patients were pseudophakic and underwent uncomplicated three-port pars plana vitrectomy, cryotherapy to the retinal breaks, and gas tamponade (14\% C3F8). Four of those six patients had an encircling band additional to the vitrectomy procedure. In all cases, the retina remained flat after RRD.

LMH was diagnosed five weeks to six months postoperatively and confirmed by Stratus OCT (Figure 1A-F). On OCT imaging, there was loss of normal concave foveal contour and decreased foveal thickness. Central foveal thickness ranged from $91 \mu \mathrm{m}$ to $165 \mu \mathrm{m}$. Snellen best-corrected visual acuity at the time of LMH diagnosis was 20/60 in two patients, 20/50 in one patient, and 20/40 in three patients (Table 1). It is noteworthy that a LMH was found in the fellow eye of one of the patients with a best-corrected visual acuity of
20/40 (Figure 1G). There was a correlation between central foveal thickness and best-corrected visual acuity; the thinner the fovea, the lower the visual acuity. OCT also showed the highly reflective line of an epiretinal membrane on the surface of the juxtafoveal retina in all six patients. Best-corrected visual acuity and OCT characteristics remained unchanged during a minimum follow-up period of two years.

\section{Discussion}

LMH formation after vitrectomy for the management of RRD is an uncommon complication. In our series, we found LMH in less than $1 \%$ of eyes that had previously undergone vitrectomy for retinal detachment. $\mathrm{LMH}$ is an acquired macular disease, and it was believed to be an abortive process of macular hole formation. ${ }^{1}$ The LMH entity is better understood with the use of optical coherence tomography and has been described as a defect with an irregular fovea contour with dehiscence of the inner from the outer layers in the fovea. ${ }^{12}$ Furthermore, OCT allowed the identification of previously misdiagnosed cases of LMH and categorized them into three tomographic categories, ie, LMH associated with an epiretinal membrane, LMH secondary to cystoid macular edema, and LMH secondary to an acute posterior vitreous detachment.

Most of the OCT studies highlight the presence of an epiretinal membrane in the majority of patients with $\mathrm{LMH},{ }^{9,22}$ suggesting that epiretinal membrane contraction may play a significant role in lamellar hole formation. We were able to identify a highly reflective line of an epiretinal membrane on the surface of the juxtafoveal retina in all six patients with LMH. The incidence of macular pucker after vitrectomy has been reported to be up to $12 \%$, while epiretinal membrane formation after scleral buckling for retinal detachment repair is estimated to be $3.5 \%-8 \%$. It has been hypothesized that the retinal pigment epithelium and other progenitor cells are dispersed more freely and in greater numbers after vitreous removal and suctioning of subretinal fluid through a peripheral break or a posterior retinotomy. ${ }^{23}$ The fact that all the lamellar holes we found in our series were in vitrectomized eyes and all six patients had an epiretinal membrane supports the hypothesis of a common triggering factor for both entities, although epiretinal membrane is a relative common finding after retinal detachment repair and its contraction does not necessarily lead to LMH formation.

LMH may also be attributable to an acute posterior vitreous detachment, as described by Androudi et al. ${ }^{22}$ Posterior vitreous detachment was reported in all of our study cases. It is possible that LMH develop as a result 


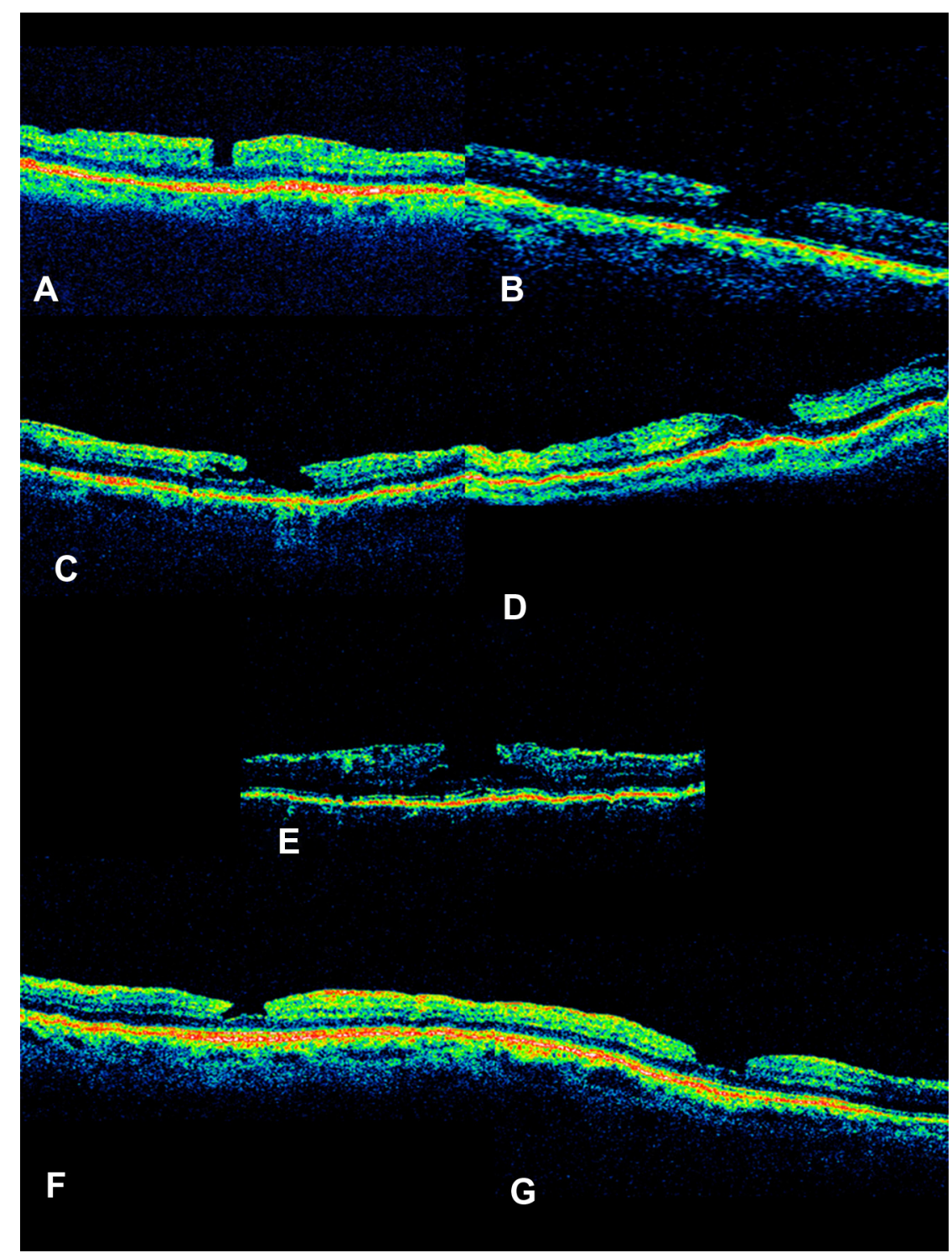

Figure I (A-F) OCT images of the six patients that developed lamellar macular holes after rhegmatogenous retinal detachment repair. (G) OCT imaging of the macula of the fellow eye of patient imaged on (F). Note also the presence of a lamellar macular hole.

Abbreviation: OCT, optical coherence tomography.

of vitreous traction during spontaneous posterior vitreous detachment or alternatively during intraoperative manipulation and induction of posterior vitreous detachment. The transmission of anteroposterior mechanical forces may cause significant vitreous traction at the fovea, with subsequent $\mathrm{LMH}$ formation. ${ }^{24} \mathrm{~A}$ question arises about the pathogenesis in patients with bilateral LMH formation. Although there are no published papers regarding genetic predisposition in patients with bilateral $\mathrm{LMH}$, there have been reports on bilateral idiopathic LMH attributed to genetic predisposition. ${ }^{25,26}$ These patients are more likely to report a family history of $\mathrm{LMH}$ than patients with unilateral $\mathrm{LMH}$, and therefore a familial component to $\mathrm{LMH}$ has been suggested in such cases.
The formation of LMH has been described in patients with diabetic cystoid edema and in chronic cystoid macular edema associated with retinal vein occlusion. Interestingly, we found no cases with LMH attributable to cystoid macular edema. The interval time between retinal detachment repair and lamellar hole detection by OCT was not significant enough to make the hypothesis for development of cystoid macular edema prior to LMH formation.

We could not detect an increase in LMH size, any changes in OCT characteristics, or in best-corrected visual acuity in our cases during the follow-up period of two years. Although many recent reports have demonstrated the efficacy of pars plana vitrectomy for LMH, especially when associated with epiretinal membranes, this treatment option was not offered 
Table I Time in months between lamellar macular hole formation and rhegmatogenous retinal detachment repair

\begin{tabular}{llll}
\hline Subject no & BCVA & $\begin{array}{l}\text { Central foveal } \\
\text { thickness (CFT) } \\
\text { in } \mu \mathbf{m}\end{array}$ & $\begin{array}{l}\text { LMH formation } \\
\text { after RRD repair } \\
\text { in months }\end{array}$ \\
\hline 1 & $20 / 50$ & 149 & 1.4 \\
2 & $20 / 40$ & 141 & 4.8 \\
3 & $20 / 60$ & 91 & 3.9 \\
4 & $20 / 40$ & 116 & 2.6 \\
5 & $20 / 60$ & 91 & 5.8 \\
6 & $20 / 40$ & 165 & 6.1 \\
\hline
\end{tabular}

Abbreviations: BCVA, best-corrected visual acuity; CFT, central foveal thickness $(\mu \mathrm{m})$

to our patients. It is uncertain if pars plana vitrectomy and internal limited membrane peeling would improve vision in a group of patients with such a severe underlying macular pathology as retinal detachment with macular involvement.

The retrospective nature of this study and the fact that OCT examination was not performed before retinal detachment repair are some of the limitations of this study, which prevented us from detecting the presence of LMH preoperatively and being able to confirm the cause of LMH formation after vitrectomy for RRD repair.

\section{Disclosure}

The authors have no proprietary interest and there was no financial support for this study.

\section{References}

1. Gass JD. Lamellar macular hole: a complication of cystoid macular edema after cataract extraction. Arch Ophthalmol. 1976;94: 793-800.

2. Unoki N, Nishijima K, Kita M, et al. Lamellar macular hole formation in patients with diabetic cystoid macular edema. Retina. 2009;29: $1128-1133$

3. Tanaka Y, Shimada N, Moriyama M, et al. Natural history of lamellar macular holes in highly myopic eyes. Am J Ophthalmol. 2011;152:96-99.

4. Shimada N, Ohno-Matsui K, Nishimuta A, et al. Detection of paravascular lamellar holes and other paravascular abnormalities by optical coherence tomography in eyes with high myopia. Ophthalmology. 2008;115: 708-717.

5. Tsukada K, Tsujikawa A, Murakami T, Ogino K, Yoshimura N. Lamellar macular hole formation in chronic cystoid macular edema associated with retinal vein occlusion. Jpn J Ophthalmol. 2011;55:506-513.

6. Trempe CL, Takahashi M, Topilow HW. Vitreous changes in retinal branch vein occlusion. Ophthalmology. 1981;88:681-687.

Clinical Ophthalmology

\section{Publish your work in this journal}

Clinical Ophthalmology is an international, peer-reviewed journal covering all subspecialties within ophthalmology. Key topics include: Optometry; Visual science; Pharmacology and drug therapy in eye diseases; Basic Sciences; Primary and Secondary eye care; Patient Safety and Quality of Care Improvements. This journal is indexed on Submit your manuscript here: http://www.dovepress.com/clinical-ophthalmology-journal
7. Michalewski J, Michalewska Z, Dzięgielewski K, Nawrocki J. Evolution frem macular pseudohole to lamellar macular hole-spectral domain OCT study. Graefes Arch Clin Exp Ophthalmol. 2011;249:175-178.

8. Wolf S, Wolf-Schnurrbusch U. Spectral-domain optical coherence tomography use in macular diseases: a review. Ophthalmologica. 2010;224:333-340.

9. Theodossiadis PG, Grigoropoulos VG, Emfietzoglou I, et al. Evolution of lamellar macular hole studied by optical coherence tomography. Graefes Arch Clin Exp Ophthalmol. 2009;247:13-20.

10. Chen JC, Lee LR. Clinical spectrum of lamellar macular defects including pseudoholes and pseudocysts defined by optical coherence tomography. Br J Ophthalmol. 2008;92:1342-1346.

11. Bottoni F, Carmassi L, Cigada M, Moschini S, Bergamini F. Diagnosis of macular pseudoholes and lamellar macular holes: is optical coherence tomography the "gold standard"? Br J Ophthalmol. 2008;92:635-639.

12. Witkin AJ, Ko TH, Fujimoto JG, et al. Redefining lamellar holes and the vitreomacular interface: an ultrahigh-resolution optical coherence tomography study. Ophthalmology. 2006;113:388-397.

13. Haouchine B, Massin P, Tadayoni R, Erginay A, Gaudric A. Diagnosis of macular pseudoholes and lamellar macular holes by optical coherence tomography. Am J Ophthalmol. 2004;138:732-739.

14. Takahashi H, Kishi S. Tomographic features of a lamellar macular hole formation and a lamellar hole that progressed to a full-thickness macular hole. Am J Ophthalmol. 2000;130:677-679.

15. Hee MR, Puliafito CA, Wong C, et al. Optical coherence tomography of macular holes. Ophthalmology. 1995;102:748-756.

16. Garcia-Arumi J, Boixadera A, Martinez-Castillo V, Zapata MA, Fonollosa A, Corcostegui B. Macular holes after rhegmatogenous retina detachment repair: surgical management and functional outcome. Retina. 2011;31:1777-1782.

17. Fabian ID, Moisseiev E, Moisseiev J, Moroz I, Barak A, Alhalel A. Macular hole after vitrectomy for primary rhegmatogenous retinal detachment. Retina. 2012;32:511-519.

18. Lee SH, Park KH, Kim JH, et al. Secondary macular hole formation after vitrectomy. Retina. 2010;30:1072-1077.

19. Kumagai K, Ogino N, Furukawa M, Larson E, Uemura A. Surgical outcomes for patients who develop macular holes after pars plana vitrectomy. Am J Ophthalmol. 2008;145:1077-1080.

20. Benzerroug M, Genevois O, Siahmed K, Nasser Z, Muraine M, Brasseur G. Results of surgery on macular holes that develop after rhegmatogenous retinal detachment. Br J Ophthalmol. 2008;92:217-219.

21. Moshfeghi AA, Salam GA, Deramo VA, et al. Management of macular holes that develop after retinal detachment repair. Am J Ophthalmol. 2003;136:895-899.

22. Androudi S, Stangos A, Brazitikos PD. Lamellar macular holes: tomographic features and surgical outcome. Am J Ophthalmol. 2009;148:420-426.

23. Katira RC, Zamani M, Berinstein DM, Garfinkel RA. Incidence and characteristics of macular pucker formation after primary retinal detachment repair by pars plana vitrectomy alone. Retina. 2008;28:744-748.

24. Rahman W, Georgalas I, da Cruz L. Macular hole formation after vitrectomy for retinal detachment. Acta Ophthalmol. 2010;88:147-148.

25. Lalin SC, Chang S, Flynn H, Von Fricken M, Del Priore LV. Familial idiopathic macular hole. Am J Ophthalmol. 2004;138:608-611.

26. Kay CN, Pavan PR, Small LB, Zhang T, Zamba GK, Cohen SM. Familial trends in a population with macular holes. Retina. 2012;32: 754-759.

\section{Dovepress}

PubMed Central and CAS, and is the official journal of The Society of Clinical Ophthalmology (SCO). The manuscript management system is completely online and includes a very quick and fair peer-review system, which is all easy to use. Visit http://www.dovepress.com/ testimonials.php to read real quotes from published authors. 